\title{
Correction to: Young athletes return too early to knee-strenuous sport, without acceptable knee function after anterior cruciate ligament reconstruction
}

\author{
Susanne Beischer ${ }^{1,2}$ - Eric Hamrin Senorski ${ }^{1,2} \cdot$ Christoffer Thomeé $^{2}$. \\ Kristian Samuelsson ${ }^{3,4} \cdot$ Roland Thomeé ${ }^{1,2}$
}

Published online: 16 November 2017

(C) European Society of Sports Traumatology, Knee Surgery, Arthroscopy (ESSKA) 2017

Correction to: Knee Surg Sports Traumatol Arthrosc

https://doi.org/10.1007/s00167-017-4747-8

The author claims that his name is incorrectly listed on PubMed. The first name should be Eric and the last name should be Hamrin Senorski. On SpringerLink the name is listed correctly, but on PubMed he is listed as Senorski EH.

The original article can be found online at https://doi.org/10.1007/s00167-017-4747-8.

Susanne Beischer

susanne.beischer@gu.se

1 Unit of Physiotherapy, Department of Health and Rehabilitation, Institute of Neuroscience and Physiology, Sahlgrenska Academy, University of Gothenburg, Box 455, 40530 Gothenburg, Sweden

2 Sportrehab Sports Medicine Clinic, Stampgatan 14, 41101 Gothenburg, Sweden

3 Department of Orthopaedics, Sahlgrenska University Hospital, Mölndal, Sweden

4 Department of Orthopaedics, Institute of Clinical Sciences, The Sahlgrenska Academy, University of Gothenburg, Gothenburg, Sweden 